\title{
Impact of mercury contamination on the population dynamics of Peringia ulvae (Gastropoda): Implications on metal transfer through the trophic web
}

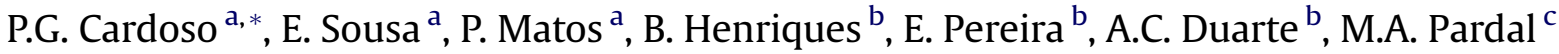 \\ a IMAR - CMA, Marine and Environmental Research Centre, Department of Life Sciences, University of Coimbra, PO Box 3046, 3001-401 Coimbra, Portugal \\ ${ }^{\mathrm{b}}$ CESAM - Centre for Environmental and Marine Studies, Department of Chemistry, University of Aveiro, 3810-193 Aveiro, Portugal \\ ${ }^{\mathrm{C}}$ CFE - Centre for Functional Ecology, Department of Life Sciences, University of Coimbra, PO Box 3046, 3001-401 Coimbra, Portugal
}

\section{A R T I C L E I N F O}

\section{Article history:}

Received 26 March 2013

Accepted 1 June 2013

Available online 14 June 2013

\section{Keywords:}

mercury

gastropod

Peringia ulvae

population dynamics

metal transfer

trophic web

\begin{abstract}
A B S T R A C T
The effects of mercury contamination on the population structure and dynamics of the gastropod Peringia ulvae (also known as Hydrobia ulvae) and its impact on the trophic web were assessed along a mercury gradient in Ria de Aveiro (Portugal). The gastropod was revealed to be a tolerant species to the contaminant, since the highest densities, biomasses and growth productivity values were recorded at the intermediate contaminated area followed by the most contaminated one and finally the least contaminated area. P. ulvae was however negatively affected by mercury in terms of growth and life span. So, in the most contaminated area the population was characterised mainly by the presence of juveniles and young individuals. The intermediate contaminated area showed a greater equilibrium in terms of groups' proportion, being the adults the dominant set. The least contaminated area presented intermediate values. P. ulvae life spans were shortest in the most contaminated area $(7-8 \mathrm{mo})$, followed by the least contaminated area (10-11 mo) and finally, the intermediate one (11-14 mo).

$P$. ulvae revealed to be an important vehicle of mercury transfer from sediments to the trophic web, incorporating approximately $15 \mathrm{~g}$ of $\mathrm{Hg}$, annually, in the inner area of the Laranjo Bay $\left(0.6 \mathrm{Km}^{2}\right)$. Therefore, despite $P$. ulvae being revealed to be not a good bio-indicator of mercury contamination, since it did not suffer profound modifications in its structure and functioning, it is a crucial element in the mercury biomagnification processes throughout the food web.
\end{abstract}

(c) 2013 Elsevier Ltd. All rights reserved.

\section{Introduction}

Mercury $(\mathrm{Hg})$ is widely distributed and has been listed as a high priority pollutant by many international agencies because of its persistence in environment and high toxicity to organisms. The fate of $\mathrm{Hg}$ distributed in sediments, has received great attention since they can act both as a major sink for or a potential source of $\mathrm{Hg}$ in aquatic environments (Yu et al., 2012 and references therein). In these systems ingestion of sediments may account for up to $100 \%$ of the total amount of metal accumulated in some deposit-feeding invertebrates (Chong and Wang, 2000 and references therein).

In contaminated environments, mercury (in the organic and inorganic forms) may be transferred from the abiotic to the biotic compartment (e.g. Baeyers et al., 2003; De Marco et al., 2006; Donkor et al., 2006). Once in biota other processes may occur,

\footnotetext{
* Corresponding author.

E-mail address: gcardoso@ci.uc.pt (P.G. Cardoso).
}

and the bioaccumulation and biomagnification throughout the food web (macroalgae, shellfish, fish) is a matter of great concern. It is recognised that anthropogenic sources of mercury are responsible for the highest environmental impacts (EPA, 1997), having deleterious effects on biota, including humans (Pan and Wang, 2011) and ecosystem functions (Boening, 2000).

Benthic invertebrates have become well established as useful bio-indicators of ecological quality in coastal systems. Numerous studies have demonstrated that benthic macrofauna respond in a predictable and relatively rapid manner to a variety of natural and anthropogenic stress (Calabretta and Oviatt, 2008 and references therein). Their sedentary condition and continuous exposure to stress conditions make them useful as bio-indicators (Calabretta and Oviatt, 2008; Dauvin, 2008).

The gastropod Peringia ulvae (Pennant 1777) also known as Hydrobia ulvae is a deposit-feeder that lives in intertidal mudflats and muddy/sandy sediments. It is also found in a wide variety of intertidal substrata, including saltmarshes or macroalgae assemblages when present at sediment or rocky surface (Sola, 1996; 
Cardoso et al., 2008). Besides that, P. ulvae, can also be a periphyton grazer (Philippart, 1995). So, its strong connection with the sediment can represent a risk of contamination for the higher trophic levels which feed on it and also may represent a threat for the functioning and success of the own species. $P$ ulvae is a key-species in several temperate estuaries, due to the great abundances and its role in the trophic web, being the link between primary producers and secondary consumers (Lillebø et al., 1999; Cardoso et al., 2008).

In the literature, there are some studies that assess the metals concentrations in water, sediment and fauna (Mucha et al., 2005; Dauvin, 2008) but very few works have been developed to evaluate the impact of metal contamination on the structure and productivity of coastal fauna (Weis et al., 2004; Rumisha et al., 2012). The scarce bibliography generally debates the effects of metal pollution at the community level and not at the population level. Assuming the relevance of this gastropod species as primary consumer, the main goal of this paper is to evaluate the impact of mercury contamination on the population dynamics of Peringia ulvae, using structural indicators such as density and biomass but also using indicators of ecosystem functioning like reproduction and secondary production. In addition, is assessed the potential of the species as vehicle of mercury transfer through the trophic web.

\section{Materials and methods}

\subsection{Study area}

The Ria de Aveiro is a shallow costal lagoon, adjacent to the Atlantic Ocean, located in the northwest coast of Portugal $\left(40^{\prime} 38^{\prime} \mathrm{N}\right.$, $8^{\prime} 44^{\prime} \mathrm{W}$ ). The system is $45 \mathrm{~km}$ long (NNE-SSW direction) with a maximum width of $10 \mathrm{~km}$ covering an area of approximately $83 \mathrm{~km}^{2}$ of wetland in high tide (spring tide) and $66 \mathrm{~km}^{2}$ in low tide. Ria de Aveiro has a complex topography, with four main channels joining and running to the mouth, several branches, islands and intertidal mud and sandflats (Fig. 1). The Ria de Aveiro has an inner area, called Laranjo Bay, which is considered the most contaminated site in the system. For approximately 5 decades (1950's1990's), this area has received discharges loaded with mercury from a chlor-alkali plant located upstream at the Estarreja industrial complex. Despite the end of the effluents release, the sediments of the Ria present high mercury concentrations, creating a spatial gradient of contamination (Coelho et al., 2005). Three sampling stations were selected in the Laranjo Bay along a transect defined by the distance from the mercury point source: station 1 was considered to be closest to the mercury point source in the lagoon, and the others stations are progressively further way, respectively $600 \mathrm{~m}$ (station 2) and $3000 \mathrm{~m}$ (station 3) (Fig. 1).

\subsection{Field and sampling procedures}

The P. ulvae population was monitored monthly, during low tide from September 2010 to September 2011. In each site, 8-10 replicates were collected randomly, with a $141 \mathrm{~cm}^{2}$ section core to a depth of approximately $20 \mathrm{~cm}$. The biological samples were all washed in situ in a $500 \mu \mathrm{m}$ mesh sieve bag and then placed into plastic bottles. All physicochemical parameters were also measured in situ (temperature, dissolved oxygen, $\mathrm{pH}$ and salinity) and water from the intertidal water pools for determination of chlorophyll $a$,

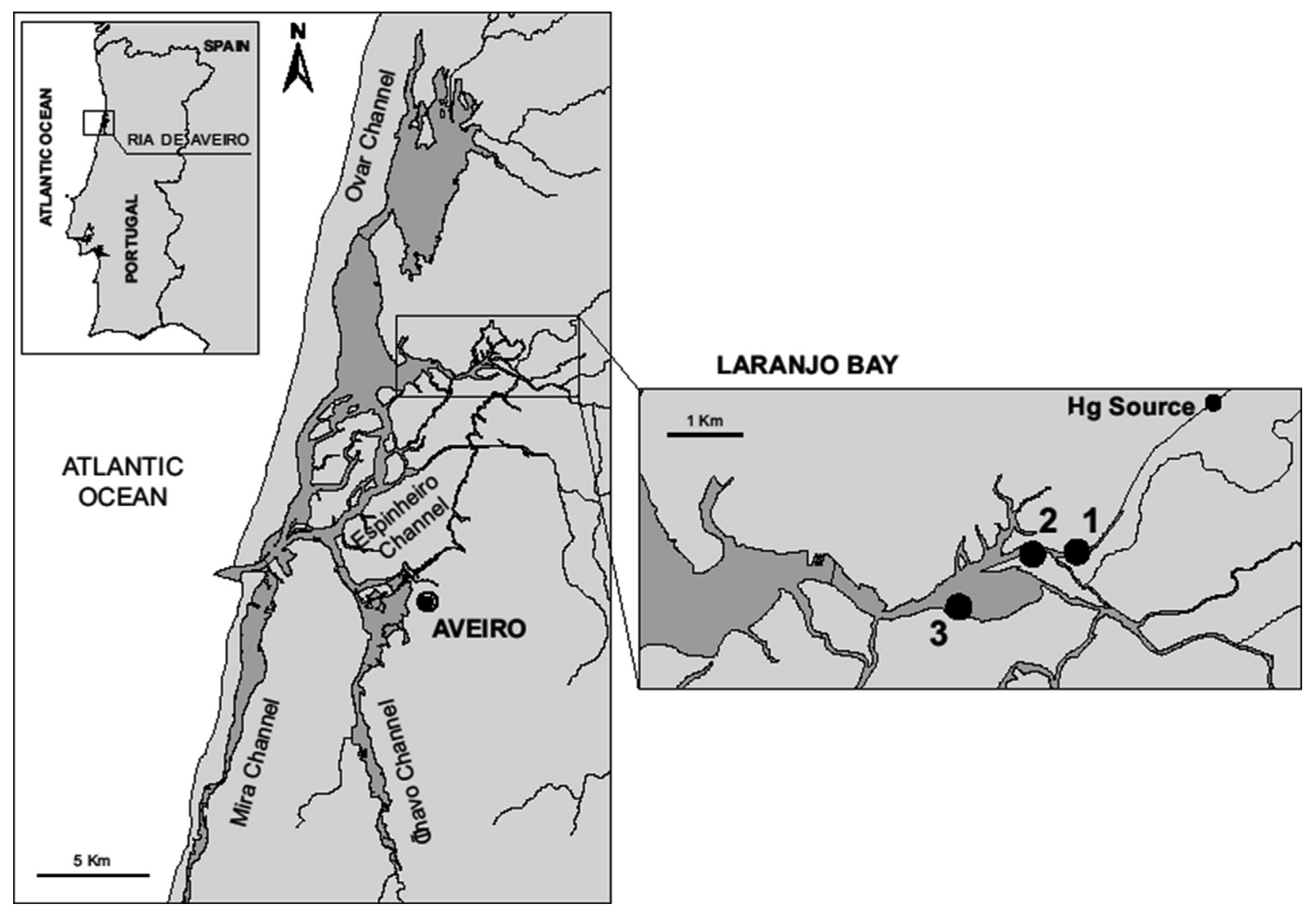

Fig. 1. Location of the sampling areas in the Ria de Aveiro. 
total dissolved mercury and total mercury in suspended particulate matter (SPM) was collected.

Sediments from each site (taken at the first 5-7 cm) were also collected for organic matter, total mercury content quantification and granulometry. They were homogenized, a portion was freezedried for mercury analysis and the remainder was oven dried at $60{ }^{\circ} \mathrm{C}$ and incinerated at $450{ }^{\circ} \mathrm{C}$ for $8 \mathrm{~h}$ for organic matter quantification. The grain size was analysed and classified according to the following nomenclature: gravel: $>2 \mathrm{~mm} ; 2.0 \mathrm{~mm}>$ coarse sand $>0.5 \mathrm{~mm} ; 0.5 \mathrm{~mm}>$ medium sand $>0.250 \mathrm{~mm} ; 0.250 \mathrm{~mm}>$ fine sand $>0.063 \mathrm{~mm} ; 0.063 \mathrm{~mm}>$ silt $>0.0039 \mathrm{~mm}$; clay $<0.0039 \mathrm{~mm}$ (adapted from Gray and Elliott, 2009).

The biological samples were fixed with $4 \%$ buffered formalin. Later, the animals were sorted and the $P$. ulvae individuals were identified and kept in $80 \%$ alcohol. They were counted and their total shell length (TSL) and maximum width (MW) were measured. A conversion equation was used, based on previous works, (TSL $=2.2289^{*} \mathrm{MW}-0.3886, n=339, r=0.97$; Lillebø et al., 1999) and the individuals were classified in different size classes (Cardoso et al., 2005; Grilo et al., 2012). Organisms for mercury determination were collected, separated by age groups, frozen and posteriorly freeze-dried for later analysis.

Length-weight relationships were determined for production estimates. Preliminary ANOVA of length $\times$ AFDW relationships indicated no significant seasonal differences, and an overall regression equation was used (AFDW $=0.0564 \mathrm{TSL}^{2.2381}, n=191$, $r=0.98$; Lillebø et al., 1999). Weight-to-weight regression (Dolbeth et al., 2005) was used to determine DW.

Cohorts were tracked using the FAO ICLARM Stock Assessment Tool package (FISAT II software) (Gayanilo and Pauly, 1997) and size frequency distributions were determined over successive sample dates. Following the cohorts since their recruitment until their disappearance (death) it is possible to estimate the life span for each cohort.

\subsection{Mercury quantifications}

\subsubsection{Sediments and organisms}

Total mercury content of the sediments and organisms was analysed by atomic absorption spectrometry with gold amalgamation, using a Leco AMA-254 (Advanced Mercury Analyser) (Costley et al., 2000). The analytical quality control of the total mercury determination was performed using Certified Reference Materials (CRMs), the TORT-2 lobster hepatopancreas for the organisms while for the sediments was used the MESS-3 (for least contaminated sediments) and PACS-2 (for high contaminated sediments). The results were corrected according to the daily recovery percentage of the CRM analyses. The values obtained for the whole CRM analysis ranged from 96.8 to $103.3 \%$ (at 0.05 significance level) for the sediments and $113 \%$ for the organisms. Analyses of CRMs were always performed in triplicate and coefficient of variation was lower than $10 \%$. Additionally, total metal contents in sediments were compared with two sediment quality guidelines (SQG), the ERL (effects range-low) and the ERM (effects range median), which define the concentration ranges that are rarely, occasionally, or frequently linked to adverse biological effects (Long et al., 1995).

\subsubsection{Water}

Water samples were filtered with $0.45 \mu \mathrm{m}$ pore size Millipore filters and acidified with concentrated $\mathrm{HNO} 3$ "mercury free" to $\mathrm{pH}<2$ and maintained in a room at $4{ }^{\circ} \mathrm{C}$. Total mercury analysis in water samples was performed by cold vapour atomic fluorescence spectroscopy (CV-AFS), on a PSA cold vapour generator, model 10.003, associated with a Merlin PSA detector, model 10.023, and using $\mathrm{SnCl} 2$ as reducing agent. This analytical methodology is highly sensitive, allowing the measurement of $1 \mathrm{ng} \mathrm{L}^{-1}$ of mercury (Mucci et al., 1995).

\subsubsection{Suspended particulate matter (SPM)}

Filters (from the previous process of water filtration) were ovendried at $60^{\circ} \mathrm{C}$ and weighted again to determine the amount of SPM. Then, they were digested with $\mathrm{HNO}_{3} 4 \mathrm{~mol} \mathrm{~L}^{-1}$ for determination of the total mercury concentration in the SPM fraction. After $\mathrm{HNO}_{3}$ digestion, the particulate total mercury was analysed by CV-AFS (Pato et al., 2008).

\subsection{Data analysis}

Some data (i.e. physicochemical variables and density/biomass of $P$. ulvae) were presented graphically as moving averages (Oct-10 to Sep-11) to minimize the effects of high-frequency variability and visually simplify the data series. Mercury concentrations were presented each two months from Sep-10 to Sep-11.

One-way ANOVAs were carried out for the environmental parameters in order to detect differences between sampling stations. In addition, statistical differences in mercury concentrations in P. ulvae as a function of sampling stations and age class were tested with two-way analysis of variance (ANOVA). All data were previously checked for normality using the Kolmogorov-Smirnov test and for homogeneity of variances using the Levene's test (Zar, 1996). Data not meeting these criteria were transformed appropriately (Zar, 1996) and checked again for normality and homocedasticity. Whenever data did not meet those criteria were applied non-parametric tests.

Chi-square tests were carried out for the P. ulvae population distributions in order to detect differences between sampling stations.

\subsection{Secondary production}

Secondary production (P) was estimated based on cohort recognition, as described in Dauvin (1986). P corresponds to the biomass assimilated in a period of time by a constant number of individuals. The growth production for each cohort was evaluated for a period between two sampling times $(t$ and $t+1)$ using the following expression:

$P=\left[\left(N_{t}+N_{t+1}\right) / 2\right]\left(\overline{\mathrm{W}}_{n+1}-\overline{\mathrm{W}}_{t}\right)$ for $\mathrm{W}_{t+1}>\mathrm{W}_{t}$

where $N$ corresponds to density (ind $\mathrm{m}^{-2}$ ) of the cohort at each sampling time and $\overline{\mathrm{w}}$ is the mean individual biomass of the cohort at each sampling time.

The total productions of each cohort were expressed as:

$P=\sum_{t=1}^{t=N}\left[\frac{N_{t}+N_{t+1}}{2}\right] d \bar{w}$

where $d \overline{\mathrm{W}}$ represents the variations of individual mean biomass of the cohort between two sampling times.

Total values of $P$ for the population were expressed as:

$P=\sum_{n=1}^{N} P_{\mathrm{cn}}$

where $P_{\mathrm{cn}}$ is the growth production of cohort $n . \overline{\mathrm{B}}$, the annual mean population biomass, is calculated as:

$\overline{\mathrm{B}}=(1 / T) \sum_{n=1}^{N} \overline{\mathrm{B}}_{n t}$

$T$ is the period of study, $N$ is the number of successive cohorts in the period $T, \overline{\mathrm{B}}_{n}$ is the mean biomass of cohort $n$; and $t$ is the duration of the cohort $n$ (Cardoso et al., 2005). 


\section{Results}

\subsection{Environmental variables}

Regarding the physicochemical parameters, the temperature, salinity and chlorophyll $a$ presented a seasonal pattern with lower values during winter and higher values during spring/summer (Fig. 2A-C). No significant differences between the three sampling areas were observed (1-way ANOVA, Temperature: $F_{2}=0.14$, $P>0.05$; Salinity: $F_{2}=0.18, P>0.05$; chlorophyll $a: F_{2}=1.35$, $P>0.05)$.

For the dissolved oxygen (DO) and pH (Fig. 2D-E) an opposite pattern was observed, with higher values during winter and lower values during spring/summer. No significant differences were observed between the three sampling areas (1-way ANOVA, DO: $\left.F_{2}=0.22, P>0.05 ; \mathrm{pH}: F_{2}=1.27, P>0.05\right)$. The organic matter (Fig. $2 \mathrm{~F}$ ) presented a quite stable pattern all over the study period with no significant differences between the sampling stations (1way ANOVA, $F_{2}=2.57, P>0.05$ ).

Concerning the granulometry, all the stations were dominated by fine sand, ranging from $50 \%$ (St. 2) to $77 \%$ (St. 3). However, no strong oscillations throughout the year were observed. Regarding most of the sediment fractions (gravel, medium sand and silt) no significant differences were observed between the sampling areas (1-way ANOVA, gravel, $F_{2}=0.18, P>0.05$; medium sand, $F_{2}=0.83$, $P>0.05$; silt, $F_{2}=0.38, P>0.05$ ), except for the coarse and fine sand fractions where significant differences were observed between stations 2 and 3 (1-way ANOVA, coarse sand, $F_{2}=6.89$, $P<0.05$; fine sand, $\left.F_{2}=5.98, P<0.05\right)$.
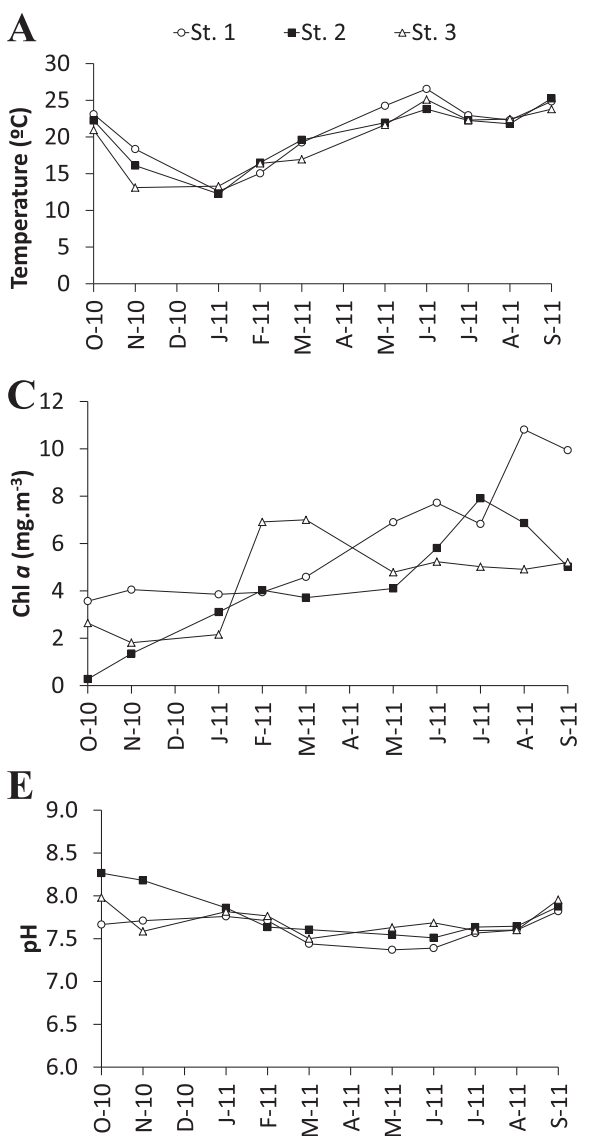

\subsection{Mercury concentrations in sediments, water and SPM}

Considering the mercury concentrations in the sediments it was clearly visible a spatial gradient (Fig. 3A). The highest levels were observed at station 1, ranging between 82 and $206 \mu \mathrm{g} \mathrm{Hg} \mathrm{g}^{-1}$. Station 2 presented intermediate values (11-24 $\mu \mathrm{g} \mathrm{Hg} \mathrm{g}^{-1}$ ), followed by station $3\left(1.3-2.0 \mu \mathrm{g} \mathrm{Hg} \mathrm{g}^{-1}\right)$ which presented residual values. Significant differences were observed between all the three sampling areas ( 1 way-ANOVA, $F_{2}=345.18, P<0.05$ ).

Regarding the total dissolved mercury in the intertidal water pools, the three stations presented a similar pattern all over the study period, showing higher values during summer (Fig. 3B). No significant differences were observed between the three areas ( 1 way-ANOVA, $F_{2}=0.63, P>0.05$ ).

Concerning the SPM fraction, stations 1 and 2 recorded similar mercury concentrations (st1 - 5-9 $\mu \mathrm{g} \mathrm{Hg} \mathrm{g}^{-1}$; st2 - 4.5$\left.11 \mu \mathrm{g} \mathrm{Hg} \mathrm{g}^{-1}\right)$ and higher than station $3\left(0.8-3 \mu \mathrm{g} \mathrm{Hg} \mathrm{g}^{-1}\right)$ (Fig. 3C). No significant differences were observed between stations 1 and 2 (Wilcoxon two-sample test, $W=59, P>0.05$ ), but significant differences were observed between the stations 1 and 3 (Wilcoxon two-sample test, $W=77, P<0.05$ ) and between the stations 2 and 3 (Wilcoxon two-sample test, $W=77, P<0.05$ ).

\subsection{Peringia ulvae density/biomass}

Concerning the density pattern, all the stations presented a similar trend with higher values during winter/spring and lower during summer. Station 2 presented higher values than stations 1 and 3 (Fig. 4A). The biomass pattern was relatively constant all over

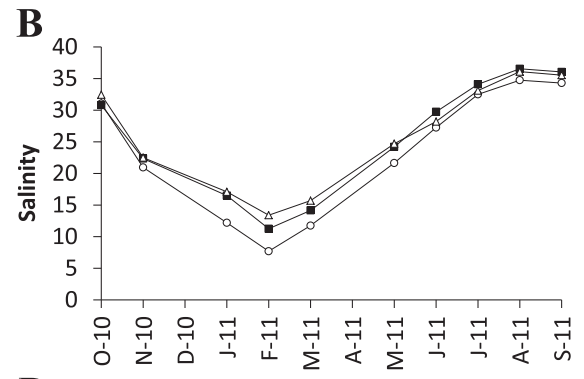

D
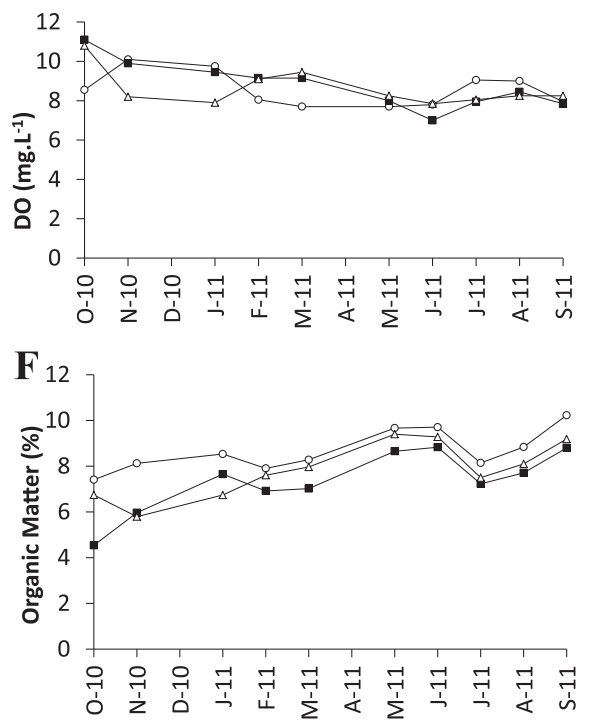

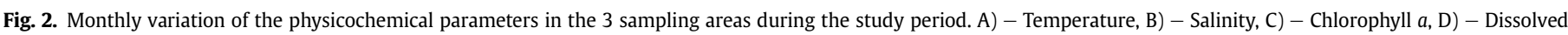
oxygen, E) - pH, F) - Organic Matter. 

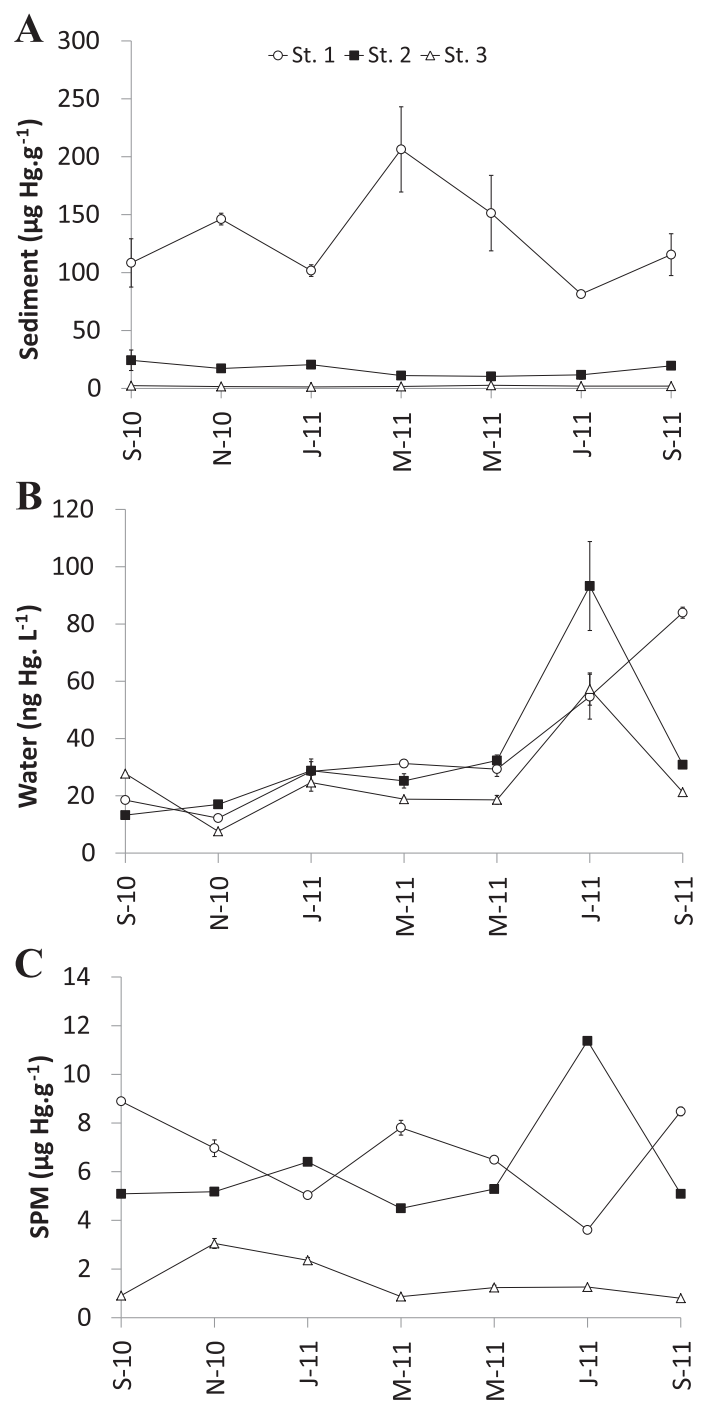

Fig. 3. Mercury concentrations in A) Sediment, B) Water and C) SPM. Error bars correspond to standard deviations.

the time for the three areas. Station 2 recorded the highest values

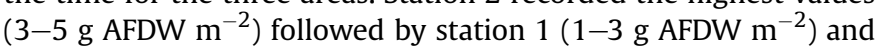
finally station 3 with the lowest values $\left(0.1-0.6 \mathrm{~g} \mathrm{AFDW} \mathrm{m}^{-2}\right.$ ) (Fig. 4B).

\subsection{Population structure and growth}

Marked differences in the population structure were observed at the three sites. At station 2 several modes were apparent in the population representing individuals of all age classes (juveniles $<2 \mathrm{~mm}$ TSL; young individuals $2-3 \mathrm{~mm}$ TSL; adults $>3 \mathrm{~mm}$ TSL (Cardoso et al., 2005). In contrast, stations 1 and 3, mainly station 1 were dominated by small individuals being significantly different from station 2 ( $\chi^{2}$ test, $P<0.05$ ) (Fig. 5). Also, population structure at station 1 was significantly different from the one at station $3\left(\chi^{2}\right.$ test, $P<0.05$ ).

Regarding the percentage of the different age groups, station 2 was dominated by adults (38\%), contrarily to stations 1 and 3 which were dominated by young individuals and juveniles (St. 1 - young ind: 47\%, juveniles: $36 \%$; St. 3 - young ind: $42 \%$, juveniles: $35 \%$ ).
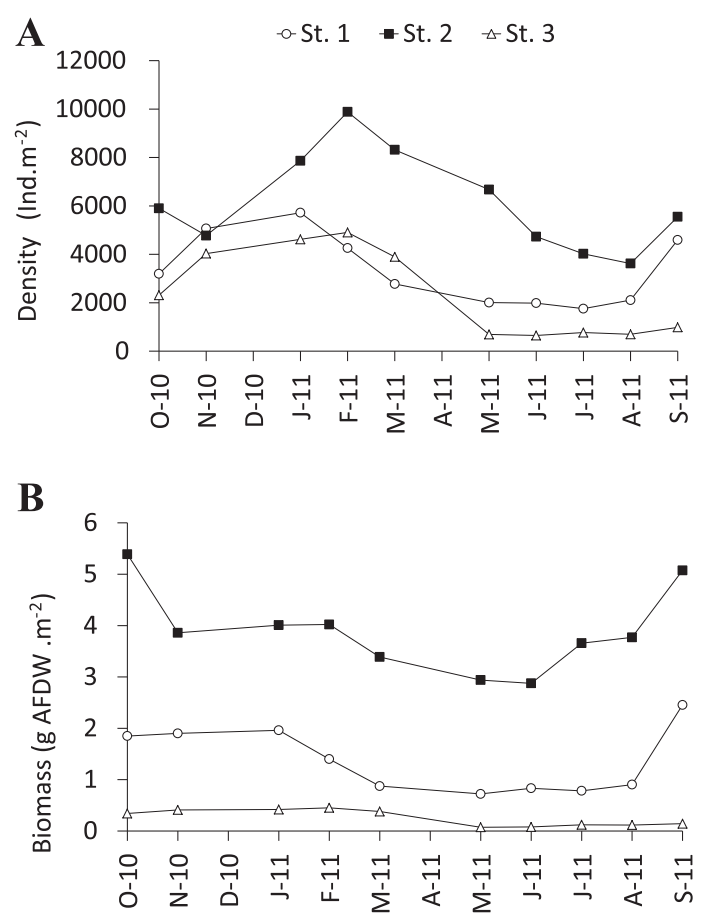

Fig. 4. Density (A) and Biomass (B) variations of Peringia ulvae in the 3 stations all over the study period.

\subsection{Life span and productivity}

Analyzing Fig. 6, it is apparent that P. ulvae presents 4 cohorts per year ( 1 spring cohort - February/March, 2 summer cohorts June and July and 1 autumn cohort - September/October) at all stations. Generally, the autumn and spring cohorts lived longer than the summer ones. At station 2 the individuals lived longer (mean: 13 months) than at station 3 (mean: 10 months) and lastly station 1 (mean: 8 months) (Table 1 ).

Growth production $(\mathrm{P})$ and mean population biomass $(\overline{\mathrm{B}})$ were considerably higher at station $2\left(185 \mathrm{~g} \mathrm{DW} \mathrm{m}^{-2} \mathrm{y}^{-1}\right)$ than at station 1 (68.96 $\mathrm{g} \mathrm{DW} \mathrm{m}^{-2} \mathrm{y}^{-1}$ ) and finally station 3 (5.55 $\mathrm{g} \mathrm{DW} \mathrm{m}^{-2} \mathrm{y}^{-1}$ ). The $\mathrm{P} / \overline{\mathrm{B}}$ ratios were slightly higher at stations 1 and 2 than at station 3 (Table 2).

\subsection{Mercury accumulation in biota}

Total mercury levels in P. ulvae were generally higher in the most contaminated area (St1) (ranging from 0.050 to $0.250 \mu \mathrm{g} \mathrm{Hg} \mathrm{g}^{-1}$ ) declining along the $\mathrm{Hg}$ gradient (St2 $-0.050-0.070 \mu \mathrm{g} \mathrm{Hg} \mathrm{g}^{-1}$, St3 $-0.030-0.050 \mu \mathrm{g} \mathrm{Hg} \mathrm{g}^{-1}$ ) (Fig. 7). Significant differences between individuals of station 1 and 2 and station 1 and 3 were observed ( 2 way ANOVA, $F_{2}=34.4, P<0.05$ ) however, no significant differences were observed between individuals of stations 2 and 3 (2-way ANOVA, $P>0.05)$. On the other hand, significant differences between juveniles and adults and between young individuals and adults were observed ( 2 -way ANOVA, $F_{2}=13.83, P<0.05$ ). Despite these differences between age classes, no metal accumulation through life was observed (Fig. 7). At station 1, a great variation in mercury concentration between age classes was observed.

Based on the estimated annual growth production values it is possible to determine the $\mathrm{Hg}$ associated to the species, annually, and consequently to assess the role of P. ulvae on the $\mathrm{Hg}$ transfer to the estuarine food web (Table 2). Production was considerably higher in the most contaminated areas (St2 - $185 \mathrm{~g} \mathrm{DW} \mathrm{m}^{-2} \mathrm{yr}^{-1}$, 
St. 1

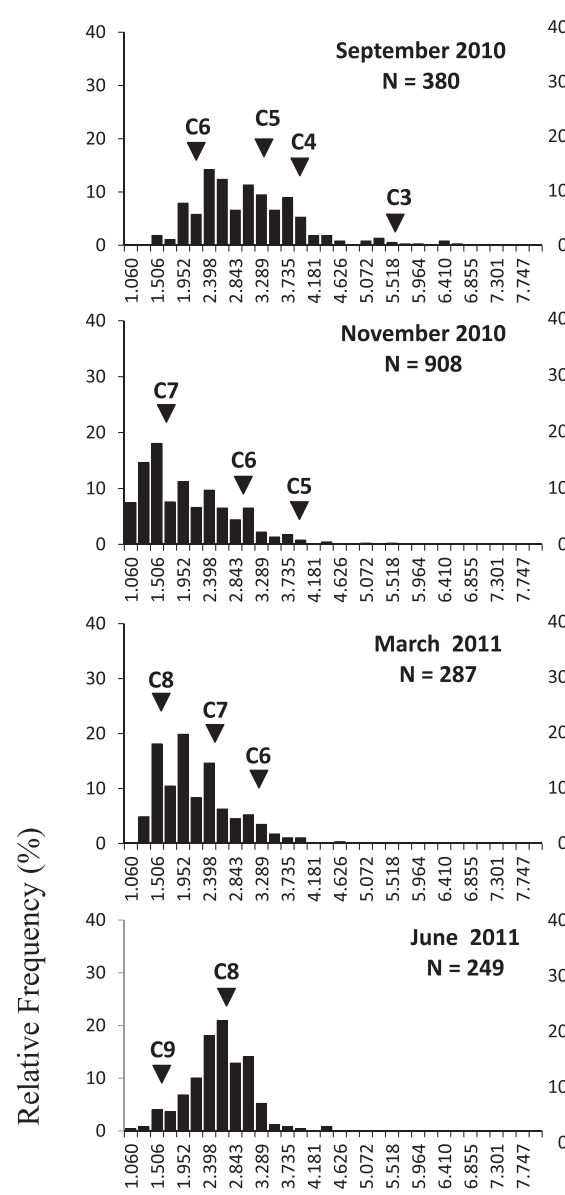

St. 2

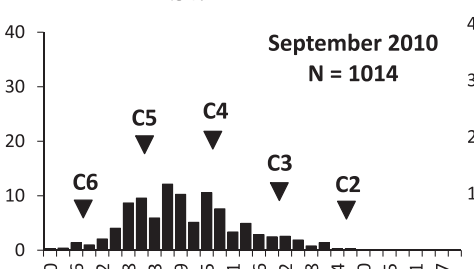

St. 3

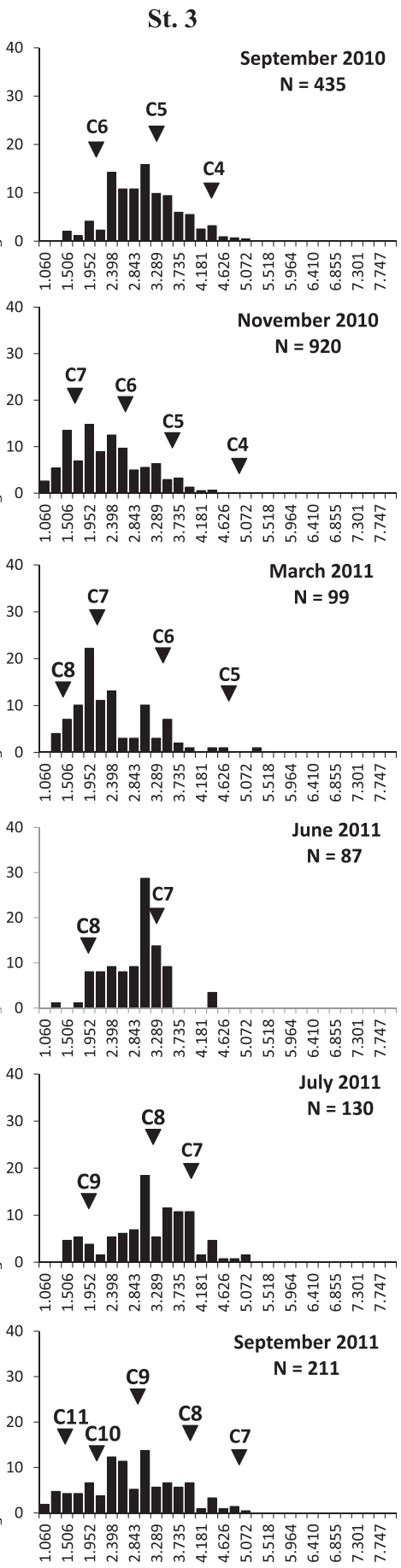

Total length $(\mathrm{mm})$

Fig. 5-. Size-frequency distribution of Peringia ulvae in the 3 stations. The cohorts (C) and the number of individuals are shown.

St1 - $68.96 \mathrm{~g} \mathrm{DW} \mathrm{m}^{-2} \mathrm{yr}^{-1}$ ) than in the least contaminated one (St3 - $42.72 \mathrm{~g} \mathrm{DW} \mathrm{m} \mathrm{m}^{-2} \mathrm{yr}^{-1}$ ). Considering the annual mercury bioaccumulation, this gastropod was responsible for the bulk $\mathrm{Hg}$ removal from the sediment, incorporating almost $31.45 \mu \mathrm{g} \mathrm{Hg} \mathrm{m}^{-2} \mathrm{yr}^{-1}$ in the intermediate contaminated area and $25.5 \mu \mathrm{g} \mathrm{Hg} \mathrm{m}^{-2} \mathrm{yr}^{-1}$ in the most contaminated area (Table 2). In the least contaminated area (St3) removal of $\mathrm{Hg}$ declined approximately $80 \%$. In fact, extrapolating the results from the three sampling stations to the approximate $0.6 \mathrm{~km}^{2}$ (St1-St3) of the intertidal flats existent in the inner Laranjo Bay, it is possible to conclude that this species is responsible for the mean annual incorporation of $12.5 \mathrm{~g}$ of $\mathrm{Hg}$ from the sediments.

\section{Discussion}

Understanding the impact of pollutants, like mercury on the structure and dynamics of benthic invertebrates is an important issue due to their impact on the food web structure and 

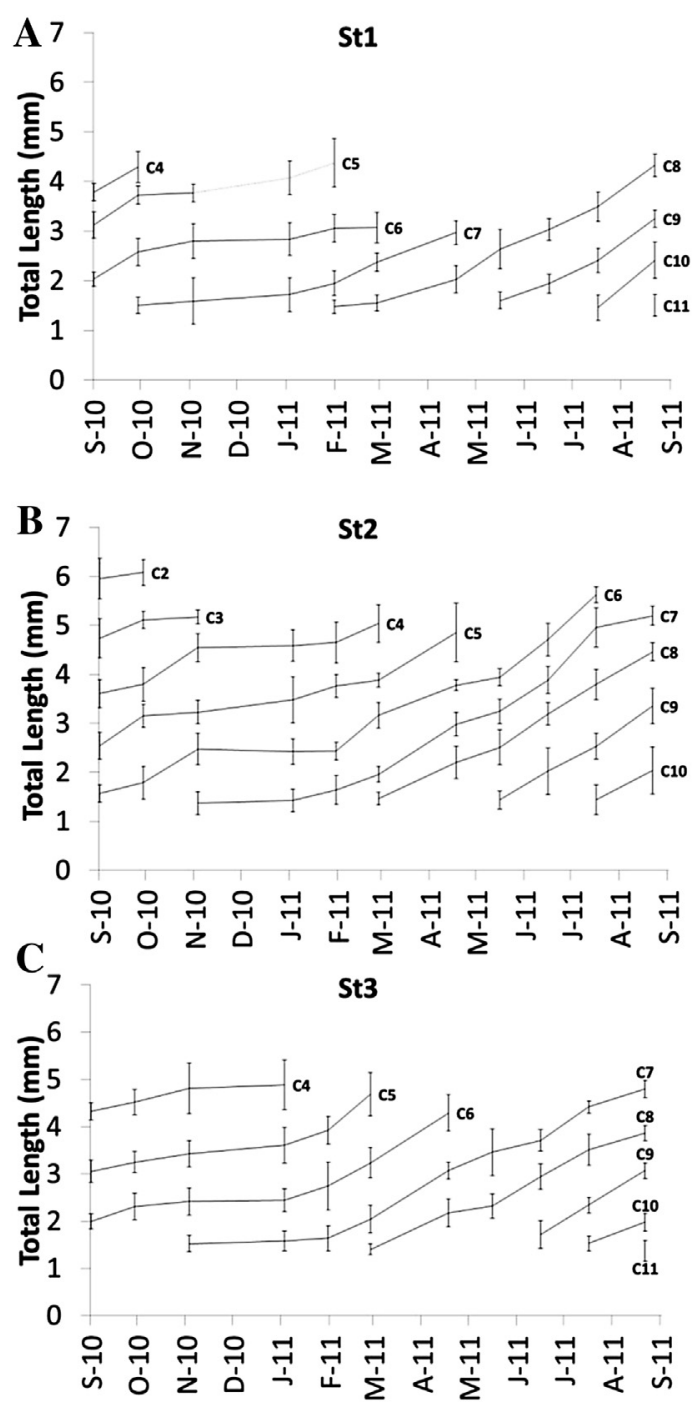

Fig. 6. Estimated growth of Peringia ulvae cohorts in the 3 stations. A) St.1, B) St.2 and C) St.3.

functioning. Benthic macroinvertebrate are usually considered good indicators of environmental health, since they are sedentary organisms and respond to the environmental impacts (Calabretta and Oviatt, 2008; Dauvin, 2008).

The present work revealed clear differences in the dynamics and structure of $P$. ulvae population along the mercury contamination gradient. This gastropod presented higher abundances and biomasses, as well as secondary production values at the intermediate contaminated area (St. 2) than at the most contaminated (St. 1) and least contaminated (St. 3) areas. This response seems to be related to the hormesis phenomenon. Hormesis represents a phenomenon in which a chemical that causes harm at greater doses paradoxically

Table 1

Estimated life span for the different cohorts (spring, summer and autumn) in the 3 stations. - Unavailable data.

\begin{tabular}{lllll}
\hline & $\begin{array}{l}\text { Spring Cohort } \\
\text { (months) }\end{array}$ & $\begin{array}{l}1^{\circ} \text { Summer } \\
\text { Cohort (months) }\end{array}$ & $\begin{array}{l}2^{\circ} \text { Summer } \\
\text { Cohort (months) }\end{array}$ & $\begin{array}{l}\text { Autumn } \\
\text { Cohort (months) }\end{array}$ \\
\hline St1 & $7-8$ & $7-8$ & $7-8$ & $7-8$ \\
St2 & $12-13$ & $10-11$ & $12-13$ & $12-14$ \\
St3 & $10-11$ & $8-9$ & $9-10$ & - \\
\hline
\end{tabular}

Table 2

Growth production estimations and associated mercury available for trophic transfer in $P$. ulvae in the 3 stations.

\begin{tabular}{lclll}
\hline & $P\left(\mathrm{~g} \mathrm{DW} \mathrm{m}^{-2} \mathrm{y}^{-1}\right)$ & $\bar{B}\left(\mathrm{~g} \mathrm{AFDW} \mathrm{m}^{-2}\right)$ & $P / \bar{B}$ & $\begin{array}{l}\text { Associated } \\
\mathrm{Hg}\left(\mu \mathrm{g} \mathrm{m}^{-2} \mathrm{y}^{-1}\right)\end{array}$ \\
\hline St1 & 68.96 & 1.23 & 3.54 & 25.52 \\
St2 & 185 & 3.58 & 3.23 & 31.45 \\
St3 & 5.55 & 1.17 & 2.34 & 5.55 \\
\hline
\end{tabular}

results in beneficial effects at a low dose (Calabrese, 2008). Hormesis has been reported to be widespread with metals, including mercury (Calabrese and Blain, 2004) and despite most references are related to experimental work, this phenomenon could be applied to the present study considering St.3 as a control, St.2 as a low dose and St.1 as a high dose. A typical hormesis response was observed in a study in which were injected mallard (Anas platyrhynchos) eggs with methylmercury chloride. In this study a case of hormesis seemed to occur because hatching success of eggs injected with the lowest dose was significantly greater (93.3\%) than that of controls (72.6\%), whereas hatching success decreased at progressively greater doses of mercury (Heinz et al., 2012). There are multiple hormetic responses, however the maximum stimulatory response (in general is $130-160 \%$ greater than the control) has become the most distinguishing characteristic of the dose-response relationship (hormesis) (Calabrese, 2008).

On the other hand, Peringia ulvae population presents a paradox, given its considerable abundance and biomass values in an area with very high levels of sediment contamination (St. 1). This is in accordance with the results obtained in the Seine estuary for the subtidal macrobenthic Abra alba-Pectinaria koreni community (Dauvin, 2008). This result also corroborates the findings of McLusky et al. (1986) which pointed out that in general, mollusks are one of the taxonomic groups least sensitive to metallic pollution compared to annelids and crustaceans. However, this fact is contrary to most of the macrobenthic species which usually present lower abundances and biomasses in the most contaminated areas (Mucha et al., 2005; Calabretta and Oviatt, 2008; Amin et al., 2009). Also, the present work is contrary to the findings of Araújo et al. (2012), which found that Peringia ulvae when exposed to sediments with different degrees of contamination (including several contaminants) avoided the most contaminated sediments by escaping to the least contaminated ones. Indeed, the greater the percentage of sediments' contamination the greater the percentage of avoidance of snails and even the organisms presented in $100 \%$ contaminated sediments suffered a reduction in their activities (Araújo et al., 2012).

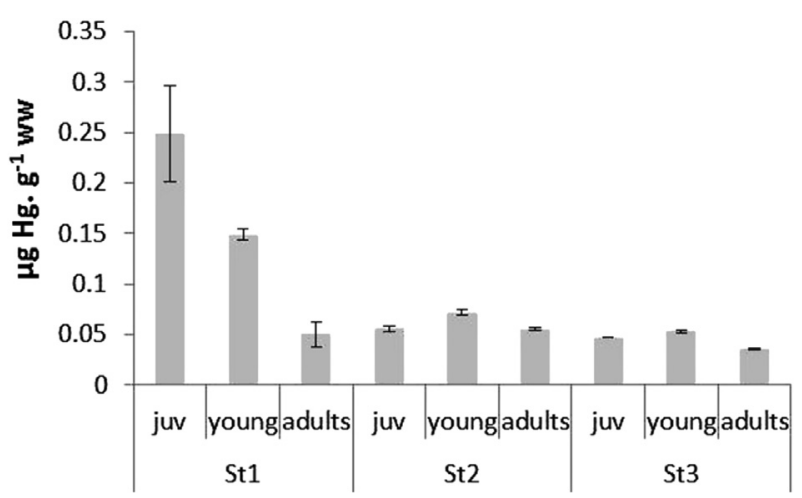

Fig. 7. Mercury accumulation in P. ulvae age classes in the 3 stations. Error bars correspond to standard errors. ww - wet weight. 
In terms of population structure and growth, P. ulvae was clearly negatively affected by the intense mercury contamination since the most contaminated area was characterized by the dominance of juveniles and young individuals. Station 1 presented the lowest percentage of adults of the three areas. It was also evident that the life span of the individuals living in the most contaminated area was strongly reduced comparatively to the other areas. Individuals from St. 2 were the ones with higher life span, followed by the ones of St3 and finally those of St.1. These results may also be related to the phenomenon of hormesis, previously explained.

According to SQG (Sediment Quality Guidelines), values much higher than ERM (effects range median) for mercury were observed at station 1, which may be responsible for the adverse biological effects observed in the P. ulvae population. According to Long et al. (1995), in sediments with mercury concentrations higher than $0.71 \mathrm{ppm}$ (ERM) the incidence of biological effects corresponds to approximately $42 \%$. Considering that at station 1 the $\mathrm{Hg}$ concentrations in the sediments ranges between 80 and $200 \mathrm{ppm}$, the incidence of biological impacts, surely would be greater. Also, according with OSPAR 2009, the EQS (Ecological Quality Standards) adopted for the $\mathrm{Hg}$ in sediments is $0.5 \mathrm{ppm}$.

In terms of growth production, the species was not greatly affected by the strong mercury concentrations since higher values were recorded at station 1 than at station 3 . This is in accordance with the higher biomasses observed in that area. So, mercury contamination seems to negatively affect the species until a certain extent, since only the growth and life span were the most affected parameters in the presence of high $\mathrm{Hg}$ concentrations. Otherwise, comparing the most contaminated area (St.1) with the least contaminated one (St. 3), the latter presented always lower abundance, biomass and productivity. In fact, $P$. ulvae was revealed to be a tolerant species to mercury. In contaminated sites, the replacement of sensitive species by pollution-tolerant species may occur (Weis et al., 2004 and references therein). For example, this gastropod revealed an opposite response compared to the bivalve Scrobicularia plana. The latter was strongly affected in terms of abundance, biomass and productivity by $\mathrm{Hg}$ contamination (personal communication). So, different groups of mollusks may respond differently to the same contaminant. This can be related with the living position and feeding guilds of the species. While P. ulvae is an epibenthic species, living in the surface of the sediment, where the metal concentrations are lower than in deeper layers, the bivalve $S$ plana is an endofaunal species which lives in direct contact with higher metal concentrations. Rumisha et al. (2012) also found that different species of mollusks responded differently to the same contaminants.

In terms of mercury bioaccumulation in this gastropod species it was observed that at station 1 (most contaminated area) a greater variability in mercury concentrations between age groups was observed compared with others stations. However, as far as possible from the discharge point, the variations in mercury concentrations due to size were minimized. The same conclusions were observed by Elliott and Griffiths (1986) for the bivalve Mytilus edulis. On the other hand, juveniles and young individuals presented always higher mercury concentrations than adults, which is contrary to some invertebrate species (e.g. Scrobicularia plana Coelho et al., 2006) that showed mercury bioaccumulation through lifespan. However, some explanations for this fact may be related with the efficiency of assimilation rates, which can be higher in younger individuals while the excretion rates may be higher in adults. Another explanation could be based on the growth dilution phenomenon. Growth dilution happens when the organism's growth is faster than its rate of metal absorption (Tavares et al., 2011). This phenomenon is typical of species with a fast growth and was also observed in some fish species, like Liza aurata (Tavares et al., 2011) and the Atlantic salmon Salmo salar (Ward et al., 2010).

Our findings are important in an environmental point of view since, $P$. ulvae is a very abundant species in intertidal areas and a common food resource for several species of predators, like waders (Cabral et al., 1999) and fishes, some of them with economic importance like, Platichthys flesus (Aarnio and Mattila, 2000), contributing to the mercury transfer from the sediments to the estuarine trophic web. In fact, $P$. ulvae is the responsible for the mean annual incorporation of approximately $15 \mathrm{~g}$ of mercury in an area of $0.6 \mathrm{Km}^{2}$. This value may seem negligible when comparing with the large amount of mercury accumulated in the Laranjo Bay sediments ( $\approx 30$ tons; Pereira et al., 2009). However, if we consider the other species that are directly associated to this gastropod, this value can have a strong relevance in terms of mercury biomagnification. Studies like the present one are important to assess the effects of contaminants on the structure and dynamics of macrobenthic species playing a key role in the functioning of the higher trophic levels.

\section{Acknowledgements}

This work was supported by FCT (Fundação para a Ciência e Tecnologia) through a project (MERCOAST) - PTDC/MAR/10916/ 2008 and by POPH and QREN - Promotion of Scientific Job funded by European Social Fund and National funds of MEC. The authors are indebted to all the colleagues that assisted in the field and lab work.

\section{References}

Aarnio, K., Mattila, J., 2000. Predation by juvenile Platichthys flesus (L.) on shelled prey species in a bare sand and a drift algae habitat. Hydrobiologia 440, 347-355.

Amin, B., Ismail, A., Arshad, A., Kong, Y.C., Kamarudin, M., 2009. Gastropod assemblages as indicators of sediment metal contamination in mangroves of Dumai, Sumatra, Indonesia. Water Air and Soil Pollution 201, 9-18.

Araújo, C.V.M., Blasco, J., Moreno-Garrido, I., 2012. Measuring the avoidance behaviour shown by the snail Hydrobia ulvae exposed to sediment with a known contamination gradient. Ecotoxicology 21, 750-758.

Baeyers, W., Leermakers, M., Papina, T., Saprykin, A., Brion, N., Noyen, J., et al., 2003. Bioconcentration and bioaccumulation of mercury and methylmercury in North Sea and Scheldt estuary fish. Archives Environmental Contamination Toxicology $45,498-508$

Boening, D.W., 2000. Ecological effects, transport, and fate of mercury: a general review. Chemosphere 40,1335-1351.

Cabral, J.A., Pardal, M.A., Lopes, R.J., Múrias, T., Marques, J.C., 1999. The impact of macroalgal blooms on the use of the intertidal area and feeding behaviour of waders (Charadrii) in the Mondego estuary (west Portugal). Acta Oecologica 20 $417-427$.

Calabrese, E.J., 2008. Hormesis: why it is important to toxicology and toxicologists. Environmental Toxicology and Chemistry 27, 1451-1474.

Calabrese, E.J., Blain, R., 2004. Metals and hormesis. Journal of Environmental Monitoring 6, 14-19.

Calabretta, C.J., Oviatt, C.A., 2008. The response of benthic macrofauna to anthropogenic stress in Narragansett Bay, Rhode Island: a review of human stressors and assessment of community conditions. Marine Pollution Bulletin 56, 1680-1695

Cardoso, P.G., Brandão, A., Pardal, M.A., Raffaelli, D., Marques, J.C., 2005. The resilience of Hydrobia ulvae populations to anthropogenic and natural disturbances. Marine Ecology Progress Series 289, 191-199.

Cardoso, P.G., Raffaelli, D., Pardal, M.A., 2008. The impact of extreme weather events on the seagrass Zostera noltii and related Hydrobia ulvae population. Marine Pollution Bulletin 56, 483-492.

Chong, K., Wang, W., 2000. Bioavailability of sediment-bound $\mathrm{Cd}, \mathrm{Cr}$ and $\mathrm{Zn}$ to the green mussel Perna viridis and the Manila clam Ruditapes philippinarum. Journal of Experimental Marine Biology and Ecology 255, 75-92.

Coelho, J.P., Pereira, M.E., Duarte, A.C., Pardal, M.A., 2005. Macroalgae response to a mercury contamination gradient in a temperate coastal lagoon (Ria de Aveiro, Portugal). Estuarine Coastal and Shelf Science 65, 492-500.

Coelho, J.P., Rosa, M., Pereira, M.E., Duarte, A.C., Pardal, M.A., 2006. Pattern and annual rates of Scrobicularia plana Mercury bioaccumulation in a human induced mercury gradient (Ria de Aveiro, Portugal). Estuarine, Coastal and Shelf Science 69, 629-635. 
Costley, C.T., Mossop, K.F., Dean, J.R., Garden, L.M., Marshall, J., Carroll, J., 2000. Determination of mercury in environmental and biological samples using pyrolysis atomic absorption spectrometry with gold amalgamation. Analytica Chimica Acta 405, 179-183.

Dauvin, J.C., 1986. Dynamique de la population d'Abra prismatica (Mollusque, Bivalve) de la baie de Morlaix (Manche Occidentale). Annales de l'Institut Oceanographique $62,1-12$

Dauvin, J.C., 2008. Effects of heavy metal contamination on the macrobenthic fauna in estuaries: the case of the Seine estuary. Marine Pollution Bulletin 57, 160-169.

De Marco, S.G., Botté, S.E., Marcovecchio, J.E., 2006. Mercury distribution in abiotic and biological compartments within several estuarine systems from Argentina: 1980-2005 period. Chemosphere 65, 213-223.

Dolbeth, M., Lillebø, A.I., Cardoso, P.G., Ferreira, S.M., Pardal, M.A., 2005. Annual production of estuarine fauna in different environmental conditions: an evaluation of the estimation methods. Journal of Experimental Marine Biology and Ecology 326, 115-127.

Donkor, A.K., Bonzongo, J.C., Nartey, V.K., Adotey, D.K., 2006. Mercury in different environmental compartments of the Pra River Bay, Ghana. Science of Tota Environment 368, 164-176.

Elliott, M., Griffiths, A.H., 1986. Mercury contamination in components of an estuarine ecosystem. Water, Science Technology 18, 161-170.

EPA-United States Environmental Protection Agency, 1997. Fate transport of mercury in environment. In: Mercury Study Report to Congress, vol. III. EPA 452/R-97-005.

Gayanilo Jr., F.C., Pauly, D., 1997. The FAO-ICLARM Stock assessment tools (FISAT) reference Manual. In: FAO Computerized Information Series (Fisheries), No. 8. FAO, Rome, p. 262.

Gray, J.S., Elliott, M., 2009. Ecology of Marine Sediments, second ed.. In: Oxford Biology, p. 215

Grilo, T.F., Cardoso, P.G., Pardal, M.A., 2012. Implications of Zostera noltii recolonization on Hydrobia ulvae population structure success. Marine Environmental Research 73, 78-84.

Heinz, G.H., Hoffman, D.J., Klimstra, J.D., Stebbins, K.R., Kondrad, S.L., Erwin, C.A. 2012. Hormesis associated with a low dose of methylmercury injected into mallard eggs. Archives of Environmental Contamination and Toxicology 62, 141-144.

Lillebø, A.I., Pardal, M.A., Marques, J.C., 1999. Population structure, dynamics and production of Hydrobia ulvae (Pennant) (Mollusca: Prosobranchia) along an eutrophication gradient in the Mondego estuary (Portugal). Acta Oecologica 20 (4), 289-304.

Long E.R. MacDonald, D.D. Smith, S.L. Calder, F.D., 1995. Incidence of adverse biological effects within ranges of chemical concentrations in marine and estuarine sediments. Environment Management 19, 81-97.
McLusky, D.S., Bryant, V., Campbell, R., 1986. The effects of temperature and salinity on the toxicity of heavy metals to marine and estuarine invertebrates. Oceanography Marine Biology 24, 481-520.

Mucci, A., Lucotte, M., Montgomery, S., Plourde, Y., Pichet, P., Tra, H.V., 1995. Mercury remobilisation from flooded soils in a hydroelectric reservoir of northern Quebec, La Grande-2: results of a soil resuspension experiment. Canadian Journal of Fish Aquatic Sciences 52, 2507-2517.

Mucha, A.P., Vasconcelos, M.T.S.D., Bordalo, A.A., 2005. Spatial and seasonal variations of the macrobenthic community and metal contamination in the Douro estuary (Portugal). Marine Environmental Research 60, 531-560.

Pan, K., Wang, W.X., 2011. Mercury accumulation in marine bivalves: influences of biodynamics and feeding niche. Environmental Pollution 159, 2500-2506.

Pato, P., Lopes, C., Válega, M., Lillebø, A.I., Dias, J.M., Pereira, E., Duarte, A.C., 2008. Mercury fluxes between an impacted coastal lagoon and the Atlantic Ocean. Estuarine, Coastal and Shelf Science 76, 787-796.

Pereira, M.E., Lillebø, A.I., Pato, P., Válega, M., Coelho, J.P., Lopes, C.B., Rodrigues, S. Cachada, A., Otero, M., Pardal, M.A., Duarte, A.C., 2009. Mercury pollution in Ria de Aveiro (Portugal): a review of the system assessment. Environmental Monitoring Assessment 155, 39-49.

Philippart, C.J.M., 1995. Effect of peryphiton grazing by Hydrobia ulvae on the growth of Zostera noltii on a tidal flat in the Dutch Wadden Sea. Marine Biology 122, 431-437.

Rumisha, C., Elskens, M., Leermakers, M., Kochzius, M., 2012. Trace metal pollution and its influence on the community structure of soft bottom molluscs in intertidal areas of the Dar es Salaam coast, Tanzania. Marine Pollution Bulletin 64, 521-531.

Sola, J.C., 1996. Population dynamics, reproduction, growth and secondary production of the mud-snail Hydrobia ulvae (Pennant). Journal of Experimental Marine Biology and Ecology 205, 49-62.

Tavares, S, Oliveira, H., Coelho, J.P., Pereira, M.E, Duarte, A.C., Pardal, M.A, 2011 Lifespan mercury accumulation pattern in Liza aurata: evidence from two southern European estuaries. Estuarine Coastal and Shelf Science 94, 315-321.

Ward, D.M., Nislow, K.H., Chen, C.Y., Folt, C.L., 2010. Rapid, Efficient growth reduces mercury concentrations in Stream-Dwelling Atlantic salmon. Transactions of the American Fisheries Society 139, 1-10.

Weis, J.S., Shurnik, J., Weis, P., 2004. Studies of a contaminated brackish marsh in the Hackensack Meadowlands of Northeastern New Jersey: benthic communities and metal contamination. Marine Pollution Bulletin 49, 1025-1035.

Yu, X., Hengxiang, L., Pan, K., Yan, Y., Wang, W.-X., 2012. Mercury distribution, speciation and bioavailability in sediments from the Pearl River Estuary, Southern China. Marine Pollution Bulletin 64, 1699-1704.

Zar, J., 1996. Biostatistical Analysis, third ed. Prentice-Hall International, Upper Saddle River, NJ, p. 662 